\title{
How conflict news comes into being: Reconstructing 'reality' through telling stories
}

Media, War \& Conflict 2018, Vol. II (I) 46-64

(C) The Author(s) 2017

Reprints and permissions: sagepub.co.uk/journalsPermissions.nav DOI: 10.1 I77/I7506352I77273/3 journals.sagepub.com/home/mwc

@SAGE

\section{Abit Hoxha and Thomas Hanitzsch}

LMU Munich, Germany

\begin{abstract}
Based on interviews with 215 conflict journalists and 315 reconstructed articles, this article explores the way conflict coverage comes into being. The study used retrospective reconstruction to investigate the genesis of news through the journalists' recollections of decisions and considerations made during the process of news production. The analysis specifically focused on story ideation, story narration and story presentation in the context of coverage about the Israeli-Palestinian conflict and the civil war in Syria, as well as about Kosovo, Macedonia, Burundi and the DRC. The study found that, when invited to speak about their jobs, many conflict journalists cling to a professional narrative suggesting that they are reporting 'just the facts' and that it is the 'reality' that tells the story. The story reconstructions demonstrate, however, that journalists deliver an intellectual reconstruction of 'reality' by actualizing the factual evidence that speaks best to the central narrative of a story and that best 'exemplifies' what they think has 'really' happened. Furthermore, journalists' habitus of routinely digesting social media and leading news outlets explains why conflict coverage is often so self-referential.
\end{abstract}

\section{Keywords}

conflict, journalists, news, production, story ideation, story narration, story presentation

\section{Introduction}

Media coverage of war and violence is a central resource for the public understanding of conflicts, and it often contributes to the development of conflicts. It is for this reason that we believe it is essential to understand the processes through which the news about conflict comes into being. Traditional research looks at conflict journalism from either an

\section{Corresponding author:}

Abit Hoxha, LMU Munich, Oettingenstrasse 67, Munich 80538, Germany.

Email: Abit.Hoxha@ifkw.Imu.de 
actor-oriented or a content-related perspective. While both perspectives have greatly contributed to our understanding of conflict news, they also produced an epistemological problem: Research based on content analysis has generated little knowledge about how the news is produced, whereas interviews with journalists tend to treat the real practices of journalists and the content they produce as a 'black box'. Furthermore, conflict journalists rarely reflect on news production routines in everyday reporting. The daily routine, which appears to the journalists as the 'natural way' of making news, may render invisible some of the factors that play out in this process in important ways. In addition, professional ideology and occupational self-consciousness may call upon journalists to deny the importance of some of these factors and cast their practice in rather idealistic terms.

Indeed, there is ample research suggesting that journalists' often idealistic imagination of their work does not fully materialize in practice or is actually contradicted by their own performance in places. Weaver et al. (2007: 233), for instance, reported only a 'modest association' between journalists' self-reported roles and the roles present in what they considered their best works. Ramaprasad and Rahman (2006) found several inconsistencies between journalists' professional orientations and their reported performance. Surveys of journalists in Chile and the US, finally, identified a gap between the professional attitudes of journalists and the content they produced (Mellado and Van Dalen, 2014; Tandoc et al., 2013). These inconsistencies are not necessarily worrisome; they can be explained by the simple fact that news content is influenced by a vast array of factors external to the journalist (Shoemaker and Reese, 2013). At the same time, however, they clearly indicate that what journalists tell the researcher in the interview is not necessarily fully reflecting their real practices.

This study tries to overcome these problems through the technique of interview-based retrospective reconstruction. This method enables the researcher to explore the genesis of a given news account through journalists' recollections of the concrete choices and considerations they made in the process of news production (Brüggemann, 2013; Reich, 2006). In the interview, we forensically reconstructed journalistic practices and editorial decisions within their very organizational and social contexts, thus generating detailed 'article biographies'. Central to this interview technique is the step-by-step reconstruction of a selected news account together with the journalist who has authored it. By confronting journalists' interview responses with the outcome of their reporting, they may become aware of the inconsistencies between their own (often idealistic) answers and their practices on the ground, which in and by itself can tell illuminating and partly unheard stories about the production of conflict news. This way, we hope we can arrive at a better understanding of the processes and routines by which journalists habitually make decisions about conflict news and which they rarely reflect upon in often hectic everyday news work.

For this purpose, we interviewed conflict reporters from three different conflict regions: the Middle East (Israel, Palestine and Syria), former Yugoslavia (Macedonia and Kosovo), and the Great Lakes region in Central Africa (Burundi and the Democratic Republic of Congo, DRC). In addition, we conducted interviews with journalists from leading media outlets in the European decision-making centres, including Belgium (Brussels), France, Germany and the UK. In the interview, we explored the various stages of news production together with the journalists who participated in this process. 
By so doing, we capitalize on the memories of journalists as an important resource for the reconstruction of news decisions.

\section{Journalists in conflict}

No literature review can do justice to the wealth of literature that has emerged in the area of conflict news production. A considerable string of literature on conflict news content and conflict/war journalists can be seen as foundational to the study of conflict news production. Despite a wealth of research in the area, we know surprisingly little about the realities journalists face on the ground and the processes of conflict news production.

Looking at news content on conflict and war, political communication scholars established a tendency among journalists to rely on official and elite sources, which seem more pronounced in times of war and conflict (Bennett, 1990; Gans, 1979). Studies examining the level of press independence found a substantive dominance of government sources and frames in conflict coverage (Bennett et al., 2007; Robinson et al., 2009). At the same time, research by Zandberg and Neiger (2005) demonstrated that journalists develop double loyalties when they cover conflicts in which they are involved or have stakes. These journalists can therefore be seen as serving two masters, as members of 'contradicting communities' - the professional and the national. While the professional community adheres to values such as objectivity, neutrality, balance and criticism, the national community demands solidarity.

Lately, this field of study has expanded more thoroughly into looking at the journalist as a subject of study. Markham (2011), criticizing that traditional studies have focused on military and political personnel, applies political phenomenology to the study of the inner workings of war correspondents' professional culture. Also, Vandevoordt (2015) looked at the economic, social and cultural capital of journalists covering war in Syria and found that when journalistic autonomy was challenged, journalists developed strategies to maintain this autonomy, but the more important finding is that the particular volume and nature of the cultural capital journalists have acquired has a qualitative impact on their perceptions and experiences and thus ultimately on their professional strategies as well' (p. 623).

The interviews with war correspondents confirm the existence of dominant norms for interpreting and acting in conflict scenarios which, while contingent upon socio-historical context, are interpreted as natural. Symbolic systems of mystification and ambivalence, which tend to reproduce professional hierarchies and structures, are dismissed by journalists with irony and cynicism, or are not present to their consciousness.

Tumber and Webster (2006) looked at technological influences in conflict news reporting by looking at the motivations, practices and conditions of journalists. They dedicate particular attention to the work of fixers and translators in the field by exploring their implicit but yet very important role in the news gathering process. In another study, Tumber and Palmer (2004) focused on embedded journalism as a news gathering technique that was popular during the 2003 Iraq campaign. They found journalists 'were slowly being enveloped into an unfamiliar occupational world of the military from which there was no chance of distancing themselves' (p. 62). This familiarization played an important role in how the events were covered. 
McLaughlin (2016) has looked at the role of war reporters and the issue of objectivity in war zones in addition to the challenges of journalistic independence, censorship, military imperatives and exposure to public relations as well as time and technological pressures in a competing media environment. He concluded that it is easier for reporters 'to tell stories of global conflict between military and economic superpowers, or a worldwide alliance against terrorism and extremism, than to explain much more complex and uncertain realities' (p. 217). Naturally, this influences objectivity of journalists to report fairly. He also found that the possibility of objectivity and impartiality in conflict zones varies according to the nature of the conflict, the level of public consensus or controversy abroad, or the extent of military censorship and restrictions in place.

What is currently missing in the literature is deeper knowledge about the production processes by which conflict news is created and about the tensions between journalists' ambitions, the structural realities of news productions and the content produced. Most studies look at the contribution of conflict journalism through the analysis of news content or through self-reports of journalists on the process of news production. Rarely do these studies link journalists' aspirations and editorial structures to the news content. Furthermore, we lack a theoretical approach that accounts for this link. The theoretical model we are suggesting below tries to close this gap by looking at news production processes through the eyes of journalists. This will allow for new and potentially innovative insights into the way the news comes into being.

\section{News production cycle}

For the purpose of this study we advance a process model of news production (see Figure 1). The model captures the three major stages in the sequence of news production, which we call 'story ideation', 'story narration' and 'story presentation'. These stages, which are partly inspired by Domingo et al. (2008), appear in a linear sequence but are in fact recursively interrelated. As many other creative endeavours, journalistic news production is a non-linear process, in which journalists often move back and forth until they feel they arrive at the optimal outcome.

Story ideation is the key process by which the story idea is generated and developed. Bantz et al. (1980) were among the first to use the term 'story ideation'. There are essentially four ways in which a story can come into being: story ideation can be proactive when journalists initiate research on a particular story idea. In this case, the impulse to build a story comes from the journalists themselves, most of the time out of their curiosity about something they have become aware of. More common, we believe, is the reactive mode of story ideation, in which the story is initiated through a person or an institution outside journalism. Journalists may attend a press conference and write about it; newsrooms may receive press releases and turn them into articles; or some kind of sensitive information is pitched (or leaked) to an investigative reporter. The third mode of story ideation we call follow-up: journalists become aware of a potential story by observing other media outlets' coverage or by revisiting an issue previously reported by themselves, their own news organization, or other media outlets. The story is therefore initiated simply by the fact that the issue already received media coverage and journalists jump on the bandwagon. Finally, story ideation can also be event-driven, for there are 


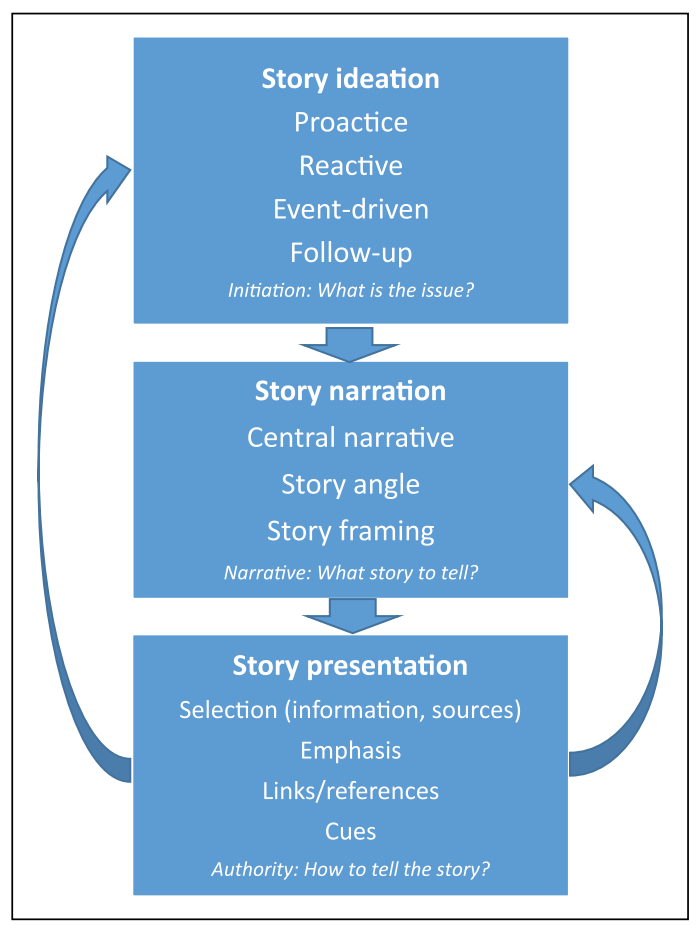

Figure I. News production process.

events that leave journalists and the media no other choice than to report on them. In this mode, journalists routinely respond to occurrences 'on the ground' that hit the established criteria of newsworthiness in a way that newsrooms feel they 'must' report on these events because everyone else will do.

Story narration refers to the development of a story narrative as well as its narrative context. While in the stage of story ideation, the emphasis is on the issue covered, story narration addresses the question of 'What story to tell'. In this regard, story narration takes account of the story-telling function of journalism - that is, every journalistic account puts the news into an established narrative that connects the present with the past, and potentially also with the future. We suggest there are three important aspects of story narration that play out in the production of news: the central narrative (the 'story'), the story angle (the perspective from which to tell the story), and the story framing (the embedding of a story within an established interpretative framework). Berger (1997) called these functions narratemes, while the sociological approach holds that the analysis of media is done both in 'content and form as a result of cultural conventions of one society at a specific time' (Becker at al., 2004: 7). Speaking about news production and narration processes, Gans (1979) and Schudson (1995) make a distinction between 'important' and 'interesting' news in terms of judgements by journalists when deciding about framing the story and angle they will take to cover the news. The two fundamental questions that are asked in this process are 'how the story is told and why it is told that 
way'. Becker et al. (2004) argue that journalists first make decisions about the design and intention of the narrative and then use narrative techniques to create a news account. Looking at the central narrative, story angle and story framing, we can further explore patterns, structures and roles of journalists in conflict news production.

Story presentation is the third in the (partly iterative) sequence of news production because it is only after a central narrative (the 'story') has been identified that journalists build the news item in a way that is consistent with the story line. In doing so, they establish discursive authority over the material, which is presented as a 'true' account of what 'really' happened. Four elements are central for the process of story presentation: selection refers to the choice of information bits (or 'facts'), sources, sound bites and any other substantive aspects that get covered in the news account. Emphasis, on the other hand, reflects the fact that not all of these elements are presented as equally important or relevant in the news account. Certain aspects, notably those that speak best to the central story narrative, are given more emphasis than others. One reason is that common occupational standards require journalists to give voice to all sides in a story, but it does not violate any professional code to emphasize certain 'facts' over others to get the story in line with the key narrative. Links and references are important because news accounts do not exist within a narrative vacuum. In their reporting, journalists consistently make reference to previous coverage - of their own, or of other colleagues or news media thereby linking their accounts to other news pieces. It is for this reason that individual news accounts can only be fully understood from within their discursive context. Cues, finally, link a news account to real-world occurrences and establish an intuitive relationship between the story narrative and an established interpretative framework. The most powerful cues in this regard are visuals, such as the picture of the 3-year-old Syrian boy who drowned in the Aegean Sea in 2015, and who has subsequently become an icon of the European failure of dealing with the refugee crisis.

It should be noted, though, that the cycle of news production does not necessarily end with the story presentation; rather, it continues its life cycle into distribution and delivery of such news to the audience, potentially leading to media effects and triggering user and audience feedback, which in turn may influence and shape conflict coverage. Furthermore, it is important to emphasize that news production is an iterative process. Often, the central narrative, angle and framing of a story may change when facts, article emphasis or cues do not support it. The narrative may also change in response to the coverage of other, notably competing, news media. Finally, a story idea might get dropped altogether if the narrative is deemed outdated or out of place, or if there are not enough facts to support the central story line.

\section{Methodology: Retrospective reconstruction of conflict news}

The overall purpose of reconstructive retrospective interviews is to qualify journalists' interview responses against the backdrop of their own content. The reconstruction interview is a fairly recent technique that was introduced to journalism research by Reich (2006, 2009, 2011) and Brüggemann (2013). The reconstruction of news stories enables the interviewer to focus 'on recording actions, not evaluating behaviour, on specific stories rather than on general estimations' (Reich, 2006: 501). The advantage of this technique is that it makes 
accessible to the researcher what often remains invisible - the news production process. Content analysis alone is inappropriate for the purpose of production studies (Manning, 2001; Reich, 2006). Thus far, scholars have found that stories were mostly implicitly initiated by sources, or other news reports (Brüggemann, 2013; McManus, 1994; Reich, 2006). By using reconstructive retrospective interviews, we reconstructed individual decisions in the news production process and the rationale behind them. Linking story content to the journalists' interview answers makes news production routines tangible and helps journalists to reflect on news decisions that were often made in a routine manner.

Hence, the primary purpose of retrospective reconstructive interviews was to study the process of conflict news production, the professional ambitions of conflict journalists and to triangulate journalists' responses with the content they produced. In order to do so, we 'confronted' the journalists with recent examples of their own work during the interview and forensically reconstructed the processes of story ideation, story narration and story presentation.

The reconstruction interviews sought to identify typical ways of how journalists generate the topics for their news stories, how they identify the story line and how they present the story. News production was therefore reconstructed from recollections of the journalists whose editorial decisions have contributed to the ultimate news account. The interviewed journalists were asked to tell the 'stories' behind their news stories. As news production processes vary across media organizations and across conflicts, we deliberately chose to focus on different types of conflict and news organizations.

This article reports results from a cross-national collaborative study of the relationship between the media, politics and conflict. For the conflicts, we selected three regions that provided us with a selection of different types of conflicts (see introduction to this special issue). In the Middle East, we focused on the Israeli-Palestinian conflict and the civil war in Syria; in the Balkan region, we selected Macedonia and Kosovo; in the Great Lakes region in Central Africa, we opted for Burundi and the Democratic Republic of Congo (DRC). In all these regions and countries, we conducted interviews with working journalists covering these conflicts on the ground. In addition, we also conducted interviews with journalists from leading media outlets in the European decision-making centres, who reported on these conflicts for their European audiences back home. For this part of the sample, we selected journalists reporting for media in Belgium (Brussels), France, Germany and the UK.

Between June 2014 and June 2015, we interviewed a full cycle of actors involved in conflict, politics and media, including journalists, non-governmental organizations, political actors and audiences. Journalists were interviewed by members of a larger research consortium consisting of eight European and Israeli institutions. The sample of journalists included members of public vs private commercial media as well as progovernment, pro-opposition, community-based and independent media outlets. The selection of media was functionally equivalent in the sense that we picked the media channels and outlets that presumably had the most significant impact on the national political and media agendas. In the European countries, this agenda-setting power was strongly exercised by national newspapers and public service broadcasting institutions. In the African countries, on the other hand, the most powerful medium was radio due to regional limited media affordances and high illiteracy rates. 


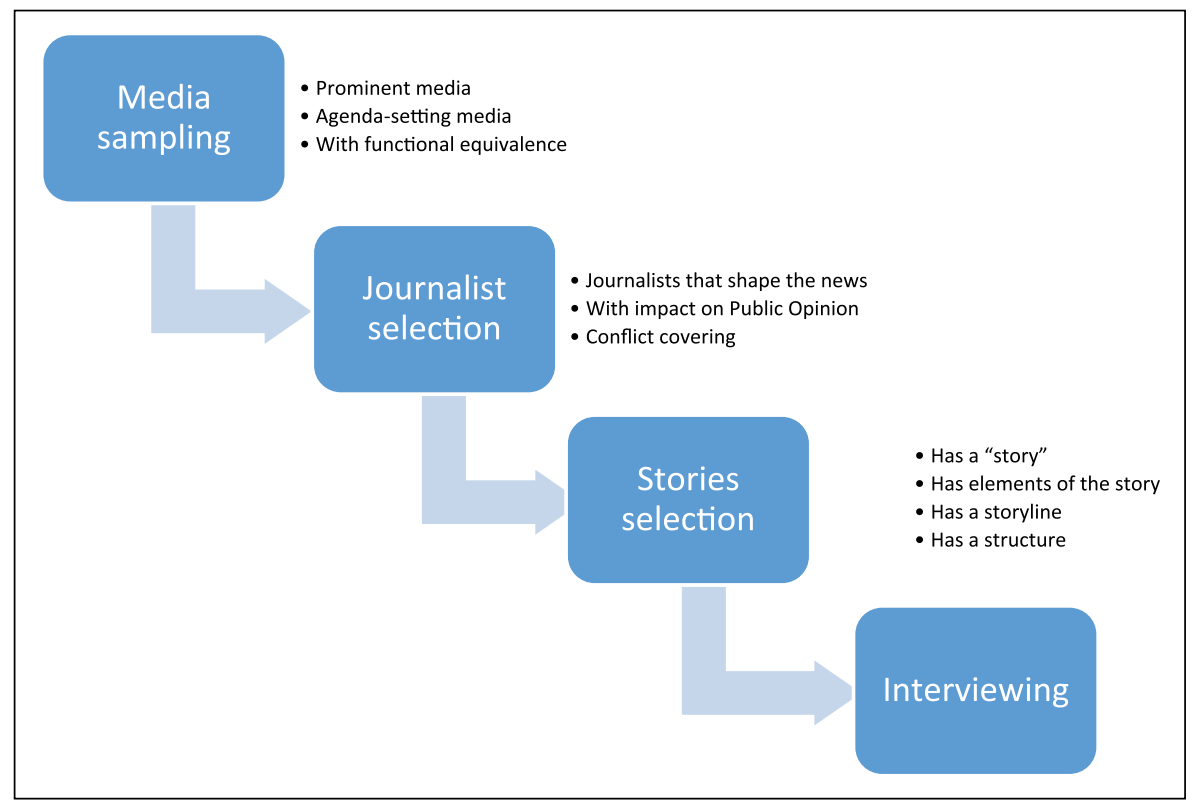

Figure 2. The process of media, journalist and story sampling for interviews.

Journalists were selected in a multi-step procedure. First, we generated profiles of conflicts and media systems on the basis of the available literature and existing country expertise. Second, we created a list of widely circulated/consumed news outlets with significant agenda-setting power for the target sample of news organizations in each country. We focused on those media outlets with higher circulation and a greater impact, including public and private media, liberal and conservative media (where applicable), and the various relevant channels (television, radio, newspapers, weeklies and online outlets).

Third, we selected conflict-related content from these media outlets and identified the authors of these stories. This work was done by researchers who spoke the local languages and who knew the cultural contexts. Fourth, and finally, we established contact with the journalists to solicit interviews. In every country, we set out to interview 20 (in the conflict regions) or 15 conflict journalists (in the European decision-making centres). The final sample consisted of 210 interviews and 314 reconstructed stories. Table 1 reports a breakdown of the sample along the 11 regions.

Before the interview, all relevant articles were forensically deconstructed into specific identifiable quotes, links, format and sources based on a coding scheme. The relevant information was then condensed into article extracts. The reconstruction of article 'biographies' was based on interviews with the authors of the selected articles, asking questions such as: 'What triggered this particular news story? Why was it published at this particular time? What sources did you approach?' Through this method, we put the process of news production in the spotlight and not the content itself. 
Table I. Media sample distribution per conflict and country.

\begin{tabular}{lcc}
\hline Country & Number of interviews & $\begin{array}{c}\text { Number of articles } \\
\text { reconstructed }\end{array}$ \\
\hline Macedonia & 19 & 36 \\
Kosovo & 18 & 36 \\
Israel & 20 & 40 \\
Palestine & 15 & 30 \\
Syria & 25 & 50 \\
Burundi & 27 & 11 \\
DR Congo & 39 & 8 \\
Germany & 17 & 34 \\
UK & 9 & 18 \\
France & 16 & 32 \\
Brussels & 10 & 19 \\
Total & $\mathbf{2 1 5}$ & $\mathbf{3 1 4}$ \\
\hline
\end{tabular}

The interviews consisted of two substantive stages: the first phase of the interview was fairly general in terms of the questions explored. We asked the journalists about how their stories were usually initiated, how much editorial freedom they have, how they choose among sources, about major influences on the news, how they see their roles as journalists and whether they think their reporting has an impact on how the audience sees the conflict. The phase of the interview was devoted to story reconstruction. We selected one very recent story and another one that covered some kind of significant event in the more distant past. Due to technical limitations, we were not able to reconstruct stories in several of the interviews made in Africa. In more than half of all other cases, we reconstructed two articles during the interviews which lasted approximately one hour.

\section{Findings}

As laid out in the conceptual lead of this article, conflict news production is a multi-step process that usually starts with the development of a story idea. In reality, this process is influenced by a variety of actors, many of which have stakes or pursue particular goals with regard to the desired outcome of media reporting. Political and military actors as well as non-governmental organizations may be interested in receiving positive coverage of their actions and activities, which is why they often feed the media with information to make sure the journalists cover the story 'properly'. This being said, journalists tend to think of their own work as 'original' in the sense that they developed the story idea independently of any external pressure or influence. In the part of the interview in which we asked more general questions about professional orientations and practices, the journalists did indeed claim the originality of their stories. However, when we 'confronted' the interviewed journalists with the content they produced, it turned out that many stories had 'occurred' to them as a result of various external forces and influences, whether that was in the form of political leaders, non-governmental organizations or other media. One 
of the most interesting findings of this study is that, as we will demonstrate below, the journalists' imagination of their work often deviated substantially from their actual practice. It is exactly there where we think the method of retrospective story reconstruction was particularly useful in our study.

For the purpose of this article, we have looked into journalists' more general reflections about their work and the story reconstructions conducted during the interview, and compared both of them to the actual content of those articles. Here, we were mainly interested in the origins of story ideas - that is, whether stories are typically pitched or leaked to the journalist, proactively searched, etc. We also asked questions about the degree of autonomy journalists usually have in choosing what to cover and whether they usually discuss stories with other journalists, including those from the other side of the conflict. Other questions focused on journalists' selection of sources, what sources they believe are trustworthy, how they verify sources and how they use social media in news production.

These questions elicited more general answers about the news production process and many of these answers pointed to more or less universal professional standards. When we discussed particular articles and confronted journalists with their own content, the answers often changed. Typical questions in the story reconstruction read as follows: 'How did you come across this particular story?' The reconstruction process continued with a discussion of sources and specific choices the journalists had made in the process of news production. The discussion deepened here because in most of the cases journalists clearly remembered the choices they had made, and why. We also asked, for instance, whether they felt - in hindsight - that there is a source missing in the story. In the following, we will specifically look into the ideation, narration and presentation of news in the two different parts of the interview: the first part dealing with more general questions about journalists' ambitions and practices, and the second part during which we reconstructed selected news accounts.

\section{Story ideation}

Ideation is a decisive step in the process of generating a story. There are various ways by which a story can arrive at a journalist's desk: reporters can proactively develop a story idea, react to information pitched to them, respond to an event that has just occurred, or follow up on other media outlets or their own previous coverage. The interviews demonstrated that conflict journalists mostly think they ideated stories in a proactive and eventdriven manner. As a journalist from Germany put it:

I think most of them (stories) originated with an idea that I have and pitch because I follow these issues and when I come across a new development or something that happens, it will usually be me who suggests writing about this.

The same journalist, when confronted with one of his own articles, explained that the motivation to write a story on de-radicalization stemmed from the simple fact that almost everyone who worked on Syria covered the story. He put it very straightforwardly in the story reconstruction: 'Everybody covering this subject was looking for somebody who was either planning to go to Syria or had just come back.' 
Journalists typically maintain extensive networks of peers within trusted circles of colleagues and they are in a constant exchange, although they restrain themselves from revealing too much to others. This peer orientation is very strong among journalists; many interviewees explained that they rely a lot on the work done by other journalists. A Palestinian journalist explained how he keeps contacts and has discussions with his peers:

There are pages on social network, mostly Facebook, that are exclusive for journalists. We meet on those pages, publish our works and discuss ideas for more reports. In short, contacts and relations between journalists are always very useful.

A French journalist working for a daily newspaper explained that he typically discusses story ideas in the newsroom as a matter of routine practice: 'It comes from each of us, in this case it comes from me, sometimes a collective discussion, but overall me, or me and a collective discussion.' The same journalist, however, was presented with his own work, and it turned out that one of the two reconstructed articles was actually triggered by a news report from another media outlet. He explains: The story 'was initiated by news there, there is a very important war between Israel and Gaza, and a major newspaper like Le Figaro, which is the French NYT (New York Times), sends a reporter on the spot.'

Similarly, a journalist from Syria noted: 'I certainly look for stories that were not tackled or highlighted by other media outlets.' When we discussed with him one of the reconstructed stories, he explained: 'It was not a follow up on a previous story, but media covered the issue in the wrong way and some pro-revolution journalists also talk incorrectly of this matter.' In the DRC, international organizations pitch stories to journalists in a routine manner: 'Sometimes here on site, OCHA (Office for the Coordination of Humanitarian Affairs) is organizing what it calls "press coffees", press conferences around which it gives us the general situation of what is happening in the humanitarian sector to the east.'

A UK journalist had a simple answer to the question of how news is usually initiated: 'It is called news. Something happens and you follow.' However, when we confronted him with the stories he produced, it turned out the story was initiated through a piece of information about children refugees pitched to the reporter. The journalist explained:

The UNICEF guy had told us about this. And then the second bit, I have a fixer in Syria, Nada, who is Syrian and she knew about this place on the front line. She hadn't been there but her sister has been there before with another journalist. Her sister is also a fixer.

The above examples demonstrate that many of the journalists we talked to emphasize their gut feeling - a mechanism acquired through professional socialization that helps the journalist identify what is an important story. Or, as a journalist from the UK put it: 'I think you have to follow your nose sometimes and I think you have just got to be quite open to the unexpected I suppose.' In the process of reconstructing the content these journalists had produced, however, they often also recognized that certain topics were covered resulting from some kind of influence from an external source. 
This is particularly true for freelance journalists, who often work on their own; for correspondents, who work with fixers and stringers in the field; and for parachute correspondents, who spend only a little time in a specific conflict area. When these journalists were asked how they came across the idea for the reconstructed work, they reported that they tend to go through social media and news as the first thing they do in the morning in an almost ritualistic manner. Social media and competing media outlets are a tremendously important source of inspiration when it comes to story ideas. As pointed out by a Palestinian journalist:

I personally read the web pages of the local Palestinian newspapers, such as Al Quds, Al Ayyam and Al Hayat al Jadida. I also read local sites, social network pages including Facebook and Twitter, Arab newspapers and a number of world media sites such as the Washington Post, US Today and The Independent.

A Syrian journalist noted that he skims through other media and social media for cross references: 'The nature of my job implies following other media outlets discussing the crisis, seeking other opinions or for professional comparison with our own product.' Clearly, freelance journalists have to invest much more time in the development of original news ideas, since they need to 'sell' their stories to the editors before they are assigned to covering it.

Journalists working for European media do rely much more on content provided by news agencies and other media (including social media) as well as on their networks of local stringers and fixers. European correspondents who are more or less permanently based in conflict areas are very dependent on their local staff. These are the people who have the necessary cultural expertise and language skills, and who get to speak to the conflict parties and citizens affected by the conflict. The importance of local contacts, stringers and fixers has also been emphasized by the journalists who work in European media and only occasionally cover a particular conflict. These European journalists often have 'no access or no local cultural knowledge' to help understand the conflict, said a German reporter. This is also true for 'parachute reporting assignments' for European journalists, which require conflict reporters to cover many stories over a few hours or days, but with little research to support them. A German journalist explained how one particular story appeared on his radar:

Two of our freelancers wrote us an e-mail yesterday saying 'we have confirmation this is going to happen tomorrow'. That is the best scenario, which means that somebody who is on our payroll says 'this is coming up, we have to cover this'. Then, of course, quite a few times you also just see your competition reporting something on Twitter.

It is exactly here where conflict coverage often becomes self-referential. Journalists often take advantage of their screening or clippings of coverage provided by the market leaders. As a UK correspondent, who wrote a story on a British airstrike in Syria, reported in the interview about her story idea: 'Reprieve gave the information to the BBC ... The $\mathrm{BBC}$ ran it and then everybody else followed.' A journalist working in Brussels, who wrote an article about refugees in Germany, was inspired by the coverage of a renowned German news magazine: 'I think that I read something about this topic on Der Spiegel.' 
Another aspect that feeds into what we described above as journalists' 'gut feeling' was their good sense of conflict development (or of outbreak of violence, in particular), which many journalists have acquired as a matter of field experience. Local journalists covering justice and security affairs in Kosovo, for instance, have a very good 'nose' for inter-ethnic violence that might follow from particular decisions made by political institutions and from statements issued by political leaders of both the Kosovo-Albanians and Kosovo-Serbs. Journalists in Macedonia reported similar experiences in relation to the ideation of news related to ethnic conflict. A Kosovar journalist explained:

The idea [for the news piece] came after we saw that the Parliament approved constitutional amendments that opened the way for the Special Court and made laws that have been passed so I and a colleague at the newspaper discussed that we want to approach this problem.

Our interviews demonstrate that most of the stories were initiated on the basis of events and prior coverage. Journalists in Kosovo and Macedonia, for instance, often claimed they were proactively seeking stories, while when we reconstructed their news accounts, we found them to be inspired by similar stories reported by other journalists. Similarly, journalists in Burundi and the DRC perceive their story selection as proactive, while in fact most of what they covered was triggered by 'something important that had happened'. A journalist in the DRC explains how news was triggered by a press release:

We focused on this [press] release there. This is where we had all the elements. The fact that we worked on their own documents on both sides, it was useless to ask questions because they were all in the final press release.

An interesting finding that we did not really account for in the conceptual approach was that sometimes stories were triggered by an absence of information. In Kosovo, most stories related to the conflict were related to negotiations between Serbia and Kosovo in Brussels. The Kosovar government was not particularly keen to make these agreements publicly available; hence, the journalists went after them. A journalist from Kosovo explained:

This idea was born from me because in the process of the dialogue [between Kosovo and Serbia] one of the points that was made was the creation of a fund that finances municipalities in the North [of Kosovo] and that helps citizens of the North. We wanted to investigate the basic idea behind it, the nature of the fund, the source of the money, the beneficiaries, the interest of the parties involved, etc.

\section{Story narration}

Story narration refers to the development of a story narrative as well as its discursive context. In the first part of the interview, during which we asked rather general questions, journalists tended to respond in a way that put their work in rather shiny terms. Journalists often argued that they had a great degree of autonomy in making decisions about what to include. A journalist from Germany said: 'I only write about things I think I have an 
opinion on to share.' In the following, however, he conceded that often he had a hard time to convince the editors that a particular story was worth covering. Furthermore, journalists often feel their intellectual freedom ends when it conflicts with editorial policy. As another journalist from Germany admitted: 'I would say I have a lot of freedom, but - and that is a big but - I am bound by the values of my agency.' It seems to us that especially the European journalists in our sample somewhat defensively maintain that they have substantial editorial autonomy in their work, even when in fact the intellectual freedom they have is much smaller than their idealistic perceptions suggest.

The development of a narrative for a story is a crucial stage in the production of news. We tend to think that nowhere is this more important than in media coverage of conflicts. In this stage, journalists are asking themselves 'what story do I want to tell'? They are likely to choose a particular story angle that anchors the central narrative advanced in the news account, which in turn frames the reported facts in a specific narrative perspective. Often, these narratives have a temporary dimension as they span across the past, present and future. This is the moment when the journalist makes a decision on where to take a particular story.

Interestingly, many journalists seem to think that the central narrative and story angle are somewhat 'inherent' to what is happening on the ground. In this view, the news is less an intellectual reconstruction of 'reality' than a true 'logical' reproduction of 'the facts'. As a British journalist noted in the interview: 'You have the wires with what's happening. And in the context of watching all political developments, then it seems most logical that this is the story you would write.' A similar observation was reported by a journalist working for Belgian media in conjunction with his coverage of the refugee crisis:

In the previous days we all saw images of refugees beaten back on the Macedonia border when trying to cross the razor wire fence. Hungary was about to do the same, as the Government planned to build a wall at the border with Serbia. I think that the story angle had defined itself.

A closer look at the interviews suggests, however, that the story narrative and angle usually result from the journalist's selective interpretation of what was happening. The same facts therefore lend themselves to often strikingly different readings of 'reality' - all of which may equally claim to report 'the truth'. The selection of the story narrative and angle is actually an essential step in the journalist's reconstruction of reality. A journalist reporting for a media outlet in Brussels explained:

I decided to show how the settlements expansion and violence against Palestinians is detrimental to the peace process. Since this process has been breaking down I thought it was important to show in detail how that was happening. The story starts from the fact that Israeli settlers smashed the face of a 6-year-old Palestinian girl by throwing a rock at her while she was going to school. She didn't die but she had severe injuries. I therefore decided to entitle this story 'Building Israel one rock at a time' to suggest that violence is part of the Israeli settlement project to take Palestinians off the land.

Furthermore, a story's key narrative does often emerge from the simple fact that some bits of information could be verified by journalists while others could not, and that if 
reporters have access to some locations and people why should this not be available to others. A British reporter admitted that often she has to construct a story when she has limited choices in terms of access to the ground and the willingness of people to talk to her:

You have to understand how difficult it is to do anything in Syria. It's not like I've got twenty different things that I can do ... And the other place I wasn't choosing particularly to interview Armenians; it was just that that was the nearest to the front line you could get and that was who happened to be living there.

\section{Story presentation}

Once a story is ideated and the key narrative, story angle and frame are determined, journalists need to establish discursive authority over the story by presenting 'true' and consistent facts in support of the story line. Hence, the selection of facts and quotes to be included and emphasized in a news account travels behind the construction of the story narrative. In the part of the interview that was about journalists' general professional orientations and practices, most journalists nevertheless maintained that facts precede the story narrative and that it is the 'facts out there' that set the stage for a certain story. Or, as a British interviewee nicely put it: 'There is no planning; this is the news. It's what happens.'

Many interviewees also make reference to the unpredictable and often surprising nature of events as they occur in an unfolding conflict. A German journalist explained in the interview: 'I am mostly the one who is stumbling over something and I want to know more. I do research and I meet people and at certain point, I get the story'. This seems to suggest that journalists are collecting facts and quotes until they arrive at the right story to tell. In other words, it is the 'reality' - the facts and quotes - that make up the story.

This may sound reassuring to many - most notably to the journalists themselves - but is simply not the reality in many cases. Journalists are confronted with a variety of (often conflicting) pieces of information. Inevitably, journalists have to make choices by selecting the facts to include and the people to quote. The following excerpt from a Palestinian journalist perfectly illustrates how journalists often readily have a narrative in mind and use the facts and quotes that substantiate this narrative. When we asked the reporter why he chose a particular angle for his story, he said:

This report broke the routine of every year reporting the start of the olive season in Hebron. This year, I decided to steer the story in a way that addresses the plight of this farmer who fights daily with the Israeli soldiers in an attempt to protect his land and his olive trees. I also seek some action in my reports.

We went on to ask how he 'built' the story. The answer was, again, very illuminating:

I started with a description of the area to allow readers to get an idea of how the place looks, I think I spoke of the farmer picking his olives while Israeli soldiers and settlers keep an eye on him. Through his story I addressed the Palestinian-Israeli conflict through the angle of land confiscation. 
At the same time, journalists often revealed in the interviews that empirical evidence - such as 'facts' and quotes - were used to 'illustrate' and 'exemplify' what they think the key narrative is or should be. Often, journalists move back and forth in this process, which means that while evidence is often fitted to the 'story', the narrative also develops as new information and perspectives are gathered. In a news article, a German reporter had quoted a person saying that 'many Jordanians are seeing us [Iraqi refugees] as cash cows.' When we asked him why he chose this quote, he said:

Because it exemplifies the main thing about it. The main thing or the first thing about Iraqis in Jordan is that they are richer than the others, but it demonstrates that they're still refugees. It exemplifies the main obstacle they are facing. They are still subjects of racism and are seen as outsiders. When he said this, I thought it was an interesting way to illuminate racism.

Just like other steps in the news production process, story presentation contains a substantial element of randomness especially in the context of conflict reporting. Not everyone is equally keen to speak to a journalist, which is particularly true for vulnerable populations. As a Brussels correspondent noted when he was doing a story about Israeli settlements and wanted to speak to some of the radical settlers in the southern hills of Hebron: 'I wanted to approach them to have their version of the story but my contacts on all sides told me that this would have been dangerous.' The story might have been a different one had this journalist talked to the settlers.

\section{Conclusions}

Our study clearly demonstrates that the production of conflict news is highly complex and involves a series of editorial decisions. Legitimizing their role as authoritative storytellers, reporters often cling to descriptions of their work that reinforce journalism's professional ideology: it is the 'reality' that tells the story, and not the journalist. In this view, journalists are witnesses of the contemporary - minute keepers who produce a first draft of history. Such an understanding is very much in line with common sense, which suggests that journalists construct the story out of 'the facts'.

The journalistic reality often looks different, as many of our interviews demonstrate. Conflicts are complicated and often have a long history loaded with meaning and interpretation. Few journalists, for instance, would be able to report on the Israeli-Palestinian conflict without having in mind a particular perspective that primes their interpretation toward a particular key narrative. In the process of making a complex conflict simple and accessible to their audiences, journalists have no choice but to make decisions about which facts to use and what to emphasize, and how. It is for this purpose that journalists - mostly inadvertently - actualize the factual evidence that speaks to the central narrative and that best 'exemplifies' what they think the essence of the story is about.

This is not to say that journalists are manipulating the facts or are 'messing' with reality. Rather, it reminds us of the simple fact that journalists are not reporting 'just the facts' but are telling stories about conflicts. There are many, equally 'true' variations depending on the key narrative the journalists choose in order to tell a meaningful story to their audience. This means that journalists have at least some power over the impact 
of their reporting on the public. Depending on the narrative the journalists use, journalistic coverage can contribute to escalation and de-escalation of conflicts. Using the same facts, journalists can narrate the tale of the ultimate 'war on terror' or a story about social inequality and political oppression - the former would call for a military solution, while the latter suggests alternative solutions.

There is one important caveat to make, however: the way many conflict journalists approach their coverage severely constrains the space of possible narratives. As many of our interviewees suggested, journalists often start out by digesting other media outlets' coverage of conflicts and take their cues from there. Few market leaders, such as the BBC, have the power to provide a key narrative for subsequent stories produced by journalists from other media outlets. Journalists' habits of screening the media for breaking news and scrolling through social media contents inevitably produce less and not more diversity of narratives and story angles. Conflict coverage thus runs the danger of becoming narrow, producing a limited range of potential and desirable political action in public discourse. This is the reason why certain political responses to conflicts (such as military intervention) often seem to be without alternative in the public conversation.

Overall, we think that researching news production through retrospective reconstruction interviews has greatly helped us to better understand the way in which conflict news is coming into being. Our study capitalizes on three bodies of evidence: the journalists' general responses in the interviews, the content they have produced in the past, and the forensic reconstruction of these stories. This way, the editorial decisions by which the journalists have contributed to the 'biography' of their articles become accessible to the researcher. We also found the theoretical framework we used for the purpose of this analysis - consisting of story ideation, story narration and story presentation - extremely useful in our analysis. ${ }^{1}$

\section{Acknowledgements}

The authors wish to thank their colleagues for their contributions. The fieldwork in Burundi, the DRC and Rwanda was conducted by Marie-Soleil Frère and Anke Fiedler (Free University of Brussels); in Macedonia by Snezana Trpevska and Igor Micevski (School of Journalism and Public Relations); in Israel and Palestine by Gadi Wolfsfeld (Interdisciplinary Center Herzliya) and Keren Tenenboim-Weinblatt (Hebrew University of Jerusalem); in Kosovo and Germany by Abit Hoxha (LMU Munich); in the UK and France by Christoph Meyer, Eva Michaels and Eric Sangar (King's College), and in Syria by research assistants from LMU Munich.

\section{Funding}

The author(s) disclosed receipt of the following financial support for the research, authorship, and/ or publication of this article: This research was funded under the 7th European Framework Program of the European Commission under Grant Agreement No 613308.

\section{Note}

1. INFOCORE is an international collaborative research project funded under the 7 th European Framework Program of the European Commission. Its main aim is to investigate the role(s) that media play in the emergence or prevention, the escalation or de-escalation, the management, resolution and reconciliation of violent conflict. 


\section{References}

Bantz CR, McCorkle S and Baade RC (1980) The news factory. Communication Research 7(1): 45-68.

Becker LB et al. (2004) The impact of newsroom philosophy on story ideation and story narration. Presented to the Midwest Association for Public Opinion Research, 19-20 November, Chicago.

Bennett WL (1990) Toward a theory of press-state relations in the United States. Journal of Communication 40(2): 103-127.

Bennett WL, Lawrence RG and Livingston S (2007) When the Press Fails: Political Power and the News Media from Iraq to Katrina. Chicago: University of Chicago Press

Berger AA (1997) Narratives in Popular Culture, Media, and Everyday Life. Thousand Oaks, CA: Sage.

Brüggemann M (2013) Transnational trigger constellations: Reconstructing the story behind the story. Journalism 14(3): 401-418.

Domingo D et al. (2008) Participatory journalism practices in the media and beyond: An international comparative study of initiatives in online newspapers. Journalism Practice 2(3): 326-342.

Gans HJ (1979) Deciding What's News. New York: Random House.

Manning P (2001) News and News Sources: A Critical Introduction. London: Sage.

Markham T (2011) The political phenomenology of war reporting. Journalism 12(5): 567-585.

McLaughlin G (2016) The War Correspondent. London: Pluto Press.

McManus JH (1994) Market-Driven Journalism: Let the Citizen Beware? Thousand Oaks, CA: Sage.

Mellado C and Van Dalen A (2014) Between rhetoric and practice: Explaining the gap between role conception and performance in journalism. Journalism Studies 15(6): 859-878.

Ramaprasad J and Rahman S (2006) Tradition with a twist: A survey of Bangladeshi journalists. International Communication Gazette 68(2): 148-165.

Reich Z (2006) The process model of news initiative: Sources lead first, reporters thereafter. Journalism Studies 7(4): 497-514.

Reich Z (2009) Sourcing the News: Key Issues in Journalism - An Innovative Study of the Israeli Press. New York: Hampton Press.

Reich Z (2011) Source credibility and journalism: Between visceral and discretional judgment. Journalism Practice 5(1): 51-67.

Robinson P, Goddard P and Murray C (2009) Testing models of media performance in wartime: U.K. TV news and the 2003 invasion of Iraq. Journal of Communication 59(3): 534-563.

Schudson M (1995) The Power of News. Cambridge, MA: Harvard University Press.

Shoemaker PJ and Reese SD (2013) Mediating the Message in the 21st Century: A Media Sociology Perspective. New York: Routledge.

Tandoc E, Hellmueller L and Vos T (2013) Mind the gap: Between role conception and role enactment. Journalism Practice 7(5): 539-554.

Tumber H and Palmer J (2004) Media at War: The Iraq Crisis. London: Sage.

Tumber H and Webster F (2006) Journalists under Fire: Information War and Journalistic Practices. London: Sage.

Vandevoordt R (2015) Why journalists covered Syria the way they did: On the role of economic, social and cultural capital. Journalism 18(5): 609-625.

Weaver D et al. (2007) The American Journalist in the 21st Century: U.S. News People at the Dawn of a New Millennium. Mahwah, NJ: Erlbaum.

Zandberg E and Neiger M (2005) Between the nation and the profession: Journalists as members of contradicting communities. Media, Culture \& Society 27(1): 131-141. 


\section{Author biographies}

Abit Hoxha is a doctoral researcher at the LMU Munich, Germany. His research focuses on comparative conflict news production.

Thomas Hanitzsch is the chair and professor of Communication at the LMU Munich, Germany. His teaching and research focuses on journalism research and comparative media studies. 